\title{
Cannibalism in invasive, native and biocontrol populations of the harlequin ladybird
}

\author{
Ashraf Tayeh ${ }^{*}$, Arnaud Estoup ${ }^{1}$, Eric Lombaert ${ }^{2,3,4}$, Thomas Guillemaud ${ }^{2,3,4}$, Natalia Kirichenko ${ }^{5}$,
} Lori Lawson-Handley ${ }^{6}$, Patrick De Clercq $^{7}$ and Benoît Facon ${ }^{1}$

\begin{abstract}
Background: Cannibalism is widespread in both vertebrates and invertebrates but its extent is variable between and within species. Cannibalism depends on population density and nutritional conditions, and could be beneficial during colonisation of new environments. Empirical studies are needed to determine whether this trait might facilitate invasion of a new area in natural systems. We investigated whether the propensity for cannibalism in H. axyridis differs both between native and invasive populations and between invasive populations from the core and from the front of the invasive area in Western Europe. We also compared the propensity for cannibalism of these natural populations with that of laboratory-reared biocontrol populations. We measured the cannibalism rates of eggs by first instar larvae and adult females at two different individual densities of ladybirds from three types of population (invasive, native and biocontrol), in laboratory-controlled conditions.

Results: Cannibalism was significantly greater in larvae from invasive populations compared to native or biocontrol populations, but there was no difference in cannibalism rates between populations from the core or front of the invaded range. Cannibalism was significantly lower in larvae from biocontrol populations compared to wild (invasive and native) populations. No differences in cannibalism rates of adult females were found between any populations. While high population density significantly increased cannibalism in both larvae and adults, the norm of reaction of cannibalism to individual density did not change significantly during the invasion and/or laboratory rearing processes.

Conclusion: This study is the first to provide evidence for a higher propensity for cannibalism in invasive populations compared to native ones. Our experiments also shed light on the difference in cannibalism evolution with respect to life stages. However, we are still at an early stage in understanding the underlying mechanisms and several different research perspectives are needed to determine whether the higher propensity for cannibalism is a general feature of the invasion process.
\end{abstract}

Keywords: Harmonia axyridis, Cannibalism, Evolution, Invasive, Native and biocontrol populations

\section{Background}

Cannibalism is ubiquitous in the animal kingdom [1,2] and probably occurs in almost all major vertebrate and invertebrate groups [3]. It is particularly common in arthropods $[4,5]$, notably in generalist predators, where it is seen as an extension of their normal predatory behaviour [6]. One common feature of cannibalism in arthropods is that victims are preferentially defenceless life stages such as eggs, young larvae or quiescent pupae [2,7]. The extent of cannibalism is highly variable between, but also within species

* Correspondence: tayeh@supagro.inra.fr

${ }^{1}$ INRA, UMR, 1062, CBGP Montpellier, France

Full list of author information is available at the end of the article
[8]. Significant genetic variation in cannibalism rate has been shown within several species (see for instance [1,911]. Moreover, experimental selection studies on the red flour beetle Tribolium castaneum have revealed that it is possible to select rapidly for strains displaying different levels of cannibalism [12,13].

Various factors can be responsible for the evolution of cannibalism rate. On the one hand, cannibalism may provide two clear benefits. First, conspecifics can be a high-quality resource, thus cannibalism may be adaptive due to its nutritional benefit, particularly when resources are limited $[2,14,15]$. Second, it may decrease the intensity of competition $[3,16]$. On the other hand, several costs

\section{Biomed Central}


may select against cannibalism, since cannibals risk acquiring pathogens or being injured or killed $[3,17]$. Also, the evolution of cannibalism in structured populations may be limited by kin selection, since individuals risk an inclusive fitness cost by eating related individuals $[18,19]$. In relation to this, a theoretical study has recently examined how different levels of dispersal affect the evolution of cannibalism and how cannibalism in turn drives the evolution of dispersal [8]. This study showed that the coevolution of cannibalism and dispersal results in the evolution of various alternative life-history strategies, with different dispersal and cannibalism regimes depending on the environmental conditions that determine initial cannibalism rates. For instance, higher dispersal rates increase the propensity for cannibalism by decreasing the relatedness between the cannibals and their prey, but high initial cannibalism rate can also drive the evolution of dispersal [8].

Cannibalism has also been suggested to be helpful in colonizing new environments $[20,21]$. It has been shown experimentally in the red flour beetle that cannibalism might facilitate colonization of a marginal environment by rescuing individuals from nutritionally poor situations through increased survival and fecundity and decreased development time [11]. Moreover, higher cannibalism rates have been shown to evolve in populations colonizing nutritionally stressful environments $[11,22]$. Via et al. [11] also stressed the need for more empirical work to test whether cannibalism might facilitate invasion of a new area in natural systems. To our knowledge, this question has not yet been investigated. The aim of the present study is to fill this gap by testing differences in cannibalism among various native, invasive and biocontrol populations of the harlequin ladybird Harmonia axyridis (Pallas, 1773) (Coleoptera: Coccinellidae).

Native to Asia, $H$. axyridis was introduced to North America and Europe as a biological control agent against aphids, and later turned invasive. Its rapid worldwide spread followed a complex invasion history involving admixture events and a prominent role of the Eastern North American outbreak [23,24]. In Europe, there is evidence for admixture between Eastern North American founders and individuals from the European biocontrol laboratory population, used locally to control aphid populations (with a contribution of biocontrol stock genes estimated around 40\%) [23]. H. axyridis is an appropriate model for studying cannibalism in the particular context of biological invasion, as well as in that of laboratory-reared biocontrol populations. Firstly, cannibalism appears to play an important role in the population dynamics of $H$. axyridis [25]. In its native area, field studies indicate that egg cannibalism may be a major mortality factor regulating population densities [26], and account for up to $60 \%$ of egg mortality [25,27]. Although egg cannibalism is most often performed by larvae, adults can also eat conspecific eggs $[7,28,29]$. Cannibalism in $H$. axyridis has been shown to provide nutritional benefits when other prey are scarce [20], nutrients are deficient, or toxic [30], and to increase survival and reduce development time $[20,30]$. Significant genetic variation in cannibalism rate has been demonstrated between individuals within population [20]. Notably, there is a strong genetic basis for the expression of cannibalism in a low food environment, whereas heritability is not significant in a higher food environment [20]. H. axyridis displays cannibalism behaviour on both sibling and non-sibling eggs. In aphidophagous coccinellids, including $H$. axyridis, sibling egg cannibalism is frequently associated with the presence of bacteria such as Wolbachia and Spiroplasma, which kill males early in their development $[31,32]$. Male-killer infected females obtain a substantial indirect fitness benefit from consuming the undeveloped male eggs from within their clutch [33]. Here, we chose to focus on non-sibling egg cannibalism to avoid any confounding effects of male-killer infection. Moreover, larvae are less likely to cannibalize related than non-related eggs [34]. Finally, we found, using the same two population transects used in this study, a marked heritable increase in flight speed of $H$. axyridis adults from the core to the front of the invasion range in Western Europe (Lombaert E, Estoup A, Joubard B, Facon B, Grégoire JC, Jannin A, Blin A, Thomas G: Rapid evolution of dispersal abilities during the expansion of the invasive ladybird Harmonia axyridis in Europe, submitted). As a theoretical study has recently showed, we could expect that this increase of dispersal may have affected the evolution of cannibalism during the spatial expansion.

The main goal of this study was to investigate whether the propensity for cannibalism in $H$. axyridis differs both between native and invasive populations and between invasive populations from the core and from the front of the invasive area in Western Europe. We were also interested in assessing possible change in this trait in laboratoryreared biocontrol populations of the same species. Finally, we examined whether the norm of reaction of cannibalism to individual density has shifted during the invasion and/ or laboratory rearing processes. To address these issues, we collected ladybirds from three types of population: 1) two populations from the native area, 2) six invasive populations sampled along two transects going from the core to the front of the invaded area in Western Europe and 3) two European biocontrol strains. We assessed cannibalism of eggs by unrelated first instar larvae and adult females of $H$. axyridis at two different individual densities, in laboratory-controlled conditions.

\section{Results}

(a) Spatial expansion in Western Europe

We did not find any significant difference in cannibalism rates by first instar larvae and adult females between populations located on the core, intermediate and front 
of the expanding range $(P=0.52$ and $P=0.81$ for larvae and adults respectively, Table 1 and Figures $1 \mathrm{~A}$ and $2 \mathrm{~A}$ ). Population identity within Western Europe did not have a significant effect on cannibalism by first instar larvae or adult females $(P=0.79$ and $P=0.93$ for larvae and adults respectively, Table 1 ).

Cannibalism by first instar larvae was globally $43 \%$ higher in the high-density treatment compared to the low-density treatment (mean number of eggs consumed per larva in $42 \mathrm{~h}=9.39$ and 6.55 for high and low density, respectively; $P=0.0002$, Table 1 and Figure 1B). Cannibalism by adult females was globally $31 \%$ higher in the highdensity treatment compared to the low-density treatment (8.24 and 6.28 eggs consumed per female per $42 \mathrm{~h}$ for high and low density, respectively; $P=0.04$, Table 1 and Figure $2 \mathrm{~B})$. We did not find any significant interaction between the individual density and the core, intermediate and front populations $(P=0.09$ and $P=0.46$ for larvae and adults respectively, Table 1$)$. This means that reaction norms according to individual density did not evolve during the spatial expansion, at least in the studied area.

\section{(b) Native versus invasive versus biocontrol populations}

We compared the cannibalism rates among the three types of population (native, invasive and biocontrol). Cannibalism by first instar larvae differed significantly between population types $(P=0.0001$, Table 1 and Figure $1 C)$. Larvae from invasive populations displayed a $37 \%$ higher cannibalism rate compared to those from native populations (7.78 and 5.69 eggs per larva per $42 \mathrm{~h}$ for invasive and native larvae, respectively; $P=0.002$, Figure $1 C$ ) and displayed twice the cannibalism rate of larvae from the biocontrol populations (3.79 eggs per larva, $P=0.0001$, Figure $1 C$ ). The native larvae cannibalized $55 \%$ more than those from the biocontrol populations $(P=0.05$, Figure $1 C$ ). There was no significant interaction between population types and density level $(P=0.71$, Table 1$)$. In contrast to the results obtained on first instar larvae, cannibalism by adult females did not differ significantly between population types neither alone $(P=0.83$, Table 1 and Figure $2 C)$ nor in interaction with density level $(P=0.67$, Table 1).

Considering the three types of populations together, we found that higher density significantly increased cannibalism by $41 \%$ in first instar larvae (mean number of eggs consumed per larva per $42 \mathrm{~h}=8.25$ and 5.87 for high and low density, respectively; $P=0.0001$, Figure 1D) and by $27 \%$ in adult females (7.96 and 6.25 eggs consumed per female per $42 \mathrm{~h}$ for high and low density, respectively; $P=0.04$, Table 1 and Figure 2D). The factor population identity was again not significant considering the three types of populations $(P=0.51$ and $P=0.65$ for larvae and adults, respectively; Table 1 ).

\section{Discussion}

We provide the first evidence that cannibalism behaviour may differ between native and invasive populations of a given species. More specifically, we found that larvae from invasive populations of $H$. axyridis in Western Europe have a higher propensity for cannibalism than larvae from the native range and from commercial laboratory-reared biocontrol populations. Cannibalism behaviour has been suggested to facilitate the colonization of marginal new environments by rescuing individuals from nutritionally poor situations [11,21]. An evolutionary increase in cannibalism linked to natural selection in such a nutritionally poor environment has been experimentally demonstrated in laboratory experiments [11,22]. A possible hypothesis is thus that upon entry into the new environment of the invasive area, $H$. axyridis larvae may have faced a nutritionally stressful situation (e.g. physiological maladaptation to the new prey, difficulty to find or capture them, or even a

Table 1 Statistical analyses of cannibalism rates by first instar larvae and adult females of $\boldsymbol{H}$. axyridis

\begin{tabular}{|c|c|c|c|c|}
\hline \multirow[b]{2}{*}{ Analysis } & \multicolumn{2}{|c|}{ First instar larvae } & \multicolumn{2}{|c|}{ Adult females } \\
\hline & Test statistic & P-value & Test statistic & P-value \\
\hline 1- Spatial expansion in Europe & $F(d f)$ & & $F(d f)$ & \\
\hline Spatial level & $0.64(2)$ & 0.5252 & $0.20(2)$ & 0.8173 \\
\hline Population (Spatial level) & $0.34(3)$ & 0.7914 & $0.15(3)$ & 0.9279 \\
\hline Density & $14.07(1)$ & $<0.0002$ & $1.19(1)$ & $<0.042$ \\
\hline Spatial level × Density & $2.38(2)$ & 0.0949 & $0.78(2)$ & 0.4556 \\
\hline \multicolumn{5}{|l|}{ 2- Different types of population } \\
\hline Population type & $17.44(2)$ & $<0.0001$ & $0.19(2)$ & 0.8262 \\
\hline Population (Population type) & $0.59(7)$ & 0.5106 & $0.72(7)$ & 0.6482 \\
\hline Density & $22.63(1)$ & $<0.0001$ & $4.34(1)$ & $<0.037$ \\
\hline Population type $\times$ Density & $0.34(2)$ & 0.7066 & $0.40(2)$ & 0.6706 \\
\hline
\end{tabular}

Note: Analysis 1- focuses on spatial expansion in Western Europe (invaded area), and analysis 2-compare different types of populations, i.e. native, invasive and biocontrol. Significant $P$-values at the $5 \%$ threshold are shown in bold. 

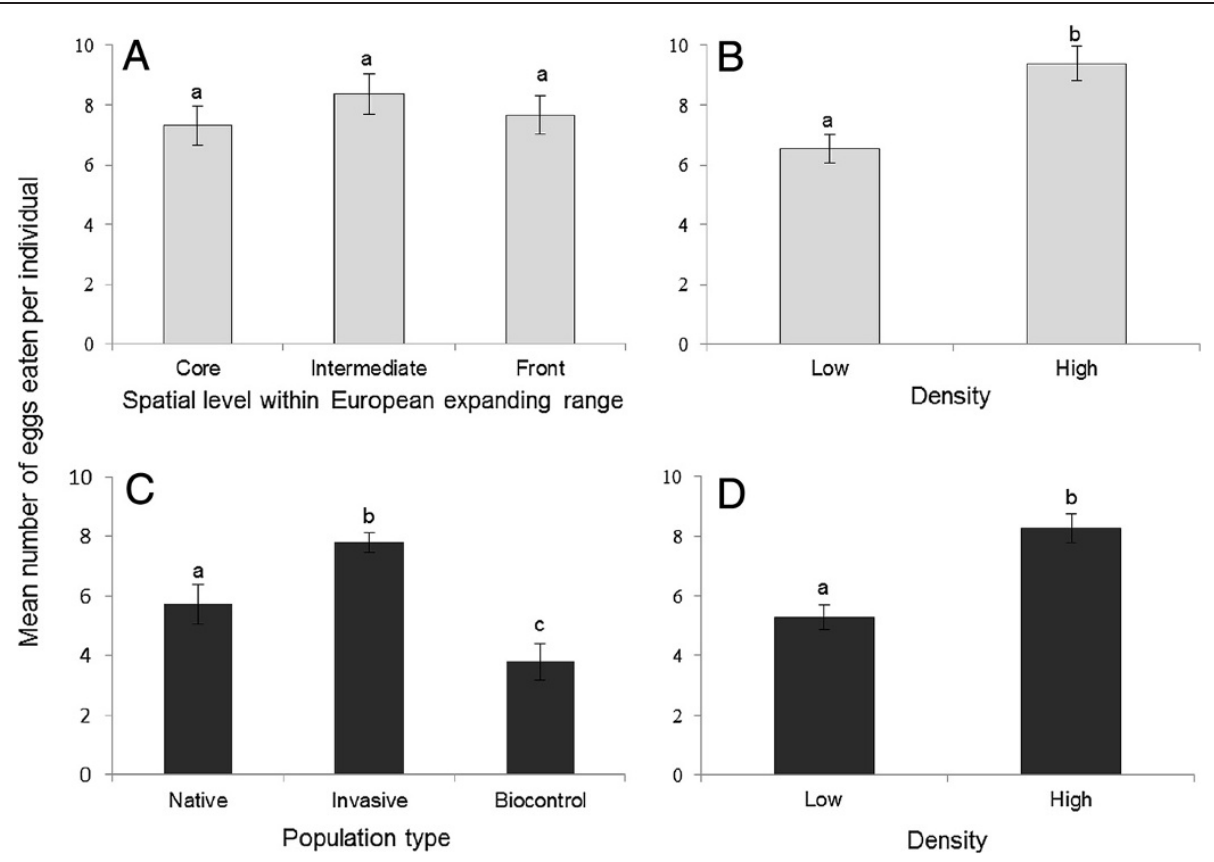

Figure 1 Mean numbers of eggs eaten per individual ( \pm standard error) by first instar larvae of $\boldsymbol{H}$. axyridis. Note: Results are given for (A) the three spatial levels within Europe expanding range (core, intermediate and front), (B) the low and high individual density treatments in data (A) pooling geographic locations, (C) three types of studied populations (i.e. Native, Invasive and Biocontrol populations), and (D) the low and high density treatments in data $\mathbf{( C )}$ pooling the different population types. Bars marked by different letters are significantly different at the 5\% threshold (P-levels are mentioned in the main text and Table 1).
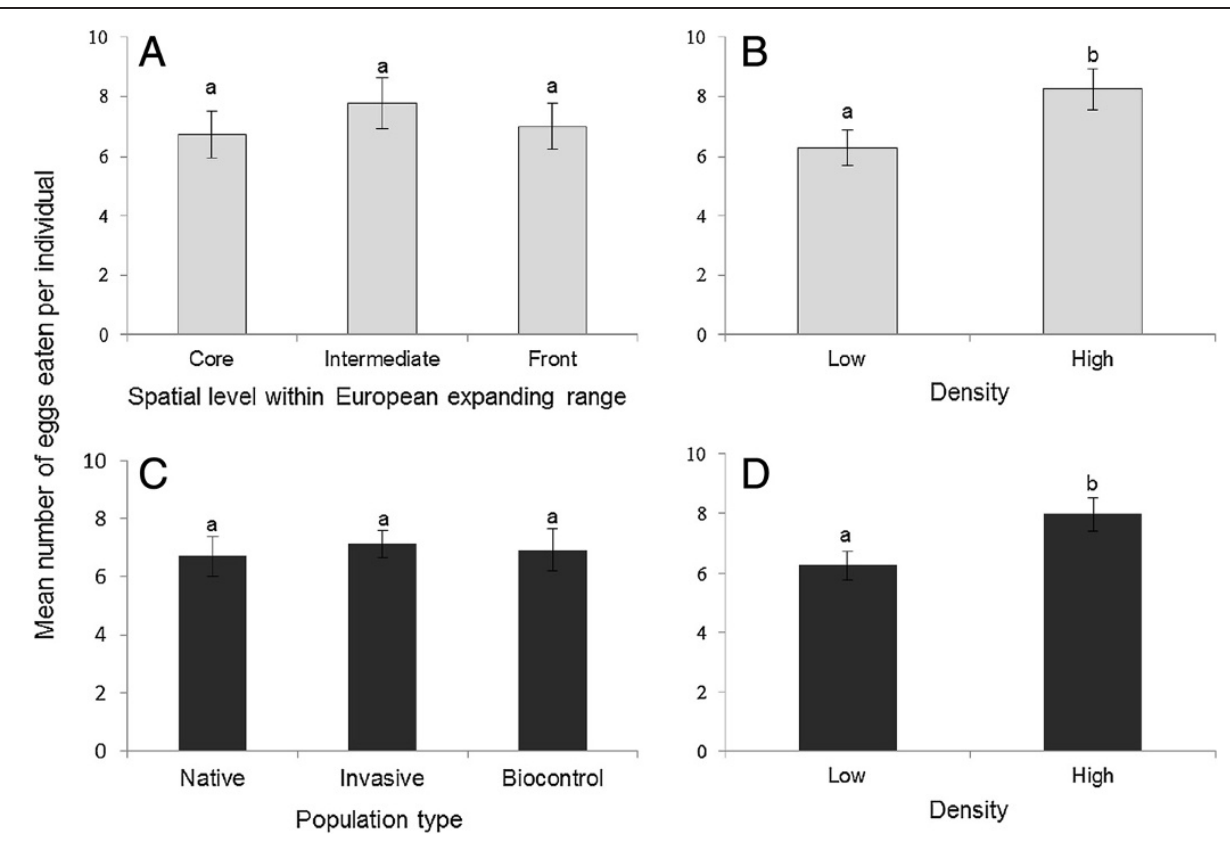

Figure 2 Mean number of eggs eaten per individual ( \pm standard error) by adult females of $\boldsymbol{H}$. axyridis. Note: Results are given for (A) the three spatial levels within Europe expanding range (core, intermediate and front), (B) the low and high individual density treatments in data (A) pooling geographic locations, (C) three types of studied populations (i.e. Native, Invasive and Biocontrol populations), and (D) the low and high density treatments in data (C) pooling the different population types. Bars marked by different letters are significantly different at the $5 \%$ threshold (P-levels are mentioned in the main text and Table 1). 
lack of temporal synchrony). $H$. axyridis mostly feeds on tree-dwelling hemipteran insects such as aphids, psyllids, and scale insects. It is known that aphid fauna differ between Asia and Europe [35], with however some species which are common between both areas. Plants, that may be used by HA to find its preys, also differ much between the two areas. Identifying the environmental differences that have selected for the observed change in cannibalism propensity would require additional work on HA foraging behavior in both areas.

Although $H$. axyridis is a generalist predator, first instar larvae tend to stay on the leaves on which they hatched [36] and their efficiency in capturing prey is very low even on prey encounter $[37,38]$. Our results, together with those of Wagner and colleagues [20], who found a higher heritability for larval cannibalism in low food environments as compared to high food environments, support the hypothesis that larval propensity for cannibalism in $H$. axyridis responds to selection in nutritionally poor situations, Another potential explanation for this higher cannibalism rate in invasive larvae could be linked to the presence of defensive alkaloids produced by predatory ladybirds against intra- and interspecific egg predation. Kajita et al. [39] showed that the amount of alkaloids could vary significantly between egg clutches within and among females in $H$. axyridis. It could thus be interesting to test whether the amount of alkaloids in eggs of invasive populations is lower than that in native ones and whether this corresponds with the higher cannibalism rate in invasive populations.

We also found that larvae from laboratory-reared biocontrol populations showed a lower propensity for cannibalism than larvae from wild native or invasive populations. This difference may result from the particular conditions of captive rearing. During mass rearing, biocontrol larvae have been fed ad libitum on highly nutritious unnatural prey (E. kuehniella eggs) over numerous generations. Such feeding regimes may have suppressed the selective pressure for cannibalism, which therefore substantially declined. It is also possible that cannibalism has been purposefully counter selected during the mass rearing process, with ladybirds displaying the cannibalism phenotype being discarded from the rearing. Although these selective explanations are attractive, we cannot at present exclude the possibility that the observed shift results from genetic drift, which is also common under laboratory rearing conditions [40], particularly as biocontrol populations are often characterized by low effective population sizes. In agreement with this, substantially lower genetic variation was found at microsatellite markers in biocontrol populations when compared to both native and invasive populations [24]. It has to be noted, however, that captive rearing has already been shown to significantly impact several other traits in biocontrol populations of $H$. axyridis, including a higher male reproductive success, a lower survival rate at lower temperatures [41] and a lower resistance to pathogens [42-44]. Altogether, it may indicate that adaptation to laboratory rearing conditions involves important reallocation of resources and energy, which is likely to affect other life history components of $H$. axyridis like fecundity and survival. Interestingly, although Western European invasive populations display a contribution of biocontrol genes estimated around $40 \%[23,24]$, these invasive populations showed a significantly higher propensity for cannibalism than biocontrol populations. This result indicates that the low propensity for cannibalism of biocontrol individuals has not been retained in the field but was rather counterselected during the genetic introgression process.

Our experiments also shed light on the difference in cannibalism evolution with respect to life stages. In contrast to larvae, invasive adults do not show any significant difference in the propensity for cannibalism compared to native and biocontrol ones. In agreement with our laboratory-based results, most of the descriptions of egg cannibalism in the field involve larvae $[25,28]$. Contrary to young larvae, which often stay on leaves on which they hatched [36], adults are able to fly long distances searching for food and may thus suffer much less from local resource scarcity. Moreover, the energetic advantage of cannibalism could be much greater for larvae than for adults.

A further aim of our study was to test whether the level of cannibalism differs between invasive populations from the core and from the front of the invaded area in Western Europe. A theoretical study has shown that higher dispersal rates can increase the probability of cannibalism but also that cannibalism itself can have important evolutionary consequences and select for increased dispersal rates [8]. Our study did not reveal any significant difference in cannibalism rates from the core to the front of the invasion range in either larvae or adults. For adults, the absence of difference along the expanding range might be explained by the same reasons as those detailed previously. For larvae, however, we suggest that the evolutionary increase of cannibalism between native and Western European invasive populations might have eroded the genetic variance at this trait, preventing a further increase in cannibalism rate along the expanding range. This is even more plausible given that Western European invasive populations correspond to a secondary introduction from a previously invaded area in Western USA [45]. This result indicates that cannibalism has not evolved conjointly with dispersal during the expansion of Western Europe. Rather, as it has been theoretically shown [8], the increased cannibalism rate in the invasive area compared to the native one may have helped the rapid increase in dispersal along the expanding range in Western Europe [8]. 
Finally, individuals often have to face recurrent bottlenecks (i.e. periods of low population density) during the invasion process, both at the time of the introduction and during the spatial expansion [45]. Because a reduced population density found at an expanding front may potentially reduce the selective advantage of cannibalism, one could have predicted a change of the norm of reaction of cannibalism to individual density during the spatial expansion of an invasive area. For both larvae and adults, we detected a higher individual rate of cannibalism at higher densities. This result is congruent with cannibalism rate being higher at higher densities in the majority of taxa $[1,2]$ and confirms that population density is a key factor in the expression of cannibalism [46]. We did not find however any significant interaction between the density and the tested populations (invasive populations located on the core, intermediate and the front of the expansion). This means that reaction norms according to density did not change during the course of invasion (at the introduction or during the spatial expansion). Interestingly, a similar result was observed for biocontrol populations of $H$. axyridis, which also endured recurrent and severe bottleneck events during their rearing in the lab.

\section{Conclusions}

This study is the first to provide evidence for a higher propensity for cannibalism in natural invasive populations compared to native ones. However, we are still at an early stage in understanding the underlying mechanisms and several research perspectives seem appealing. For instance, since $H$. axyridis now has a worldwide distribution (Asia, Africa, South America, North America, Europe) [47], the study of cannibalism behaviour in invaded continents other than Europe would allow to determine whether the higher propensity for cannibalism in invasive populations is a general feature of the invasion process at the worldwide scale. In addition, it has been suggested that enhanced cannibalism might be a transient phenomenon in the new environment, with cannibalism rates increasing initially and then declining as physiological adaptation to new prey increases and the nutritional benefits of cannibalism thereby diminish $[11,22]$. It would hence be interesting to test whether higher cannibalism rates are maintained in the European invasive populations in the long term.

\section{Methods}

\section{(a) Sampling of populations and rearing conditions}

A total of ten $H$. axyridis populations of three different types (native, invasive and biocontrol) were used in this study. The first observations of established feral $H$. axyridis populations in Europe were made in 2001 near Ghent and Brussels in Belgium. A rapid demographic and spatial expansion to a large part of Europe has subsequently been observed $[47,48]$. We thus considered the centre of Belgium as the invasion core. Based on the information about the spatial expansion given by the French national $H$. axyridis survey (http://vinc.ternois.pagespersoorange.fr/cote_nature/Harmonia_axyridis/), we collected six populations, sampled between October and November 2010, along two transects (three samples per transect) ranging from the invasion core of the European outbreak (Brussels area) towards the invasion front in southern and western France (Figure 3, Table 2). The six population samples used in this study are part of the same spatial expansion of a unique outbreak originating from a single introduction event as demonstrated by using analyses based on microsatellite markers. Two samples were also collected from the native range of $H$. axyridis in 2009 (Krasnoyarsk in Russia and Fuchu in Japan). Sampling was conducted in public location that did not require specific authorization, and did not involved endangered or protected species. Finally, we used two $H$. axyridis samples from commercial biocontrol stocks (from Biotop and Biobest biocontrol companies), both of which were derived around 1995 from a strain reared under laboratory conditions since 1982. Founding insects of those laboratory populations were probably collected in China by INRA (Institut National de Recherche Agronomique, France) $[24,49]$. Before the experiments started, we reared all the populations in the laboratory for at least three generations $\left(G_{0}\right.$ to $\left.G_{3}\right)$, under strictly controlled conditions, in order to avoid bias due to maternal effects. In all experiments, individuals were fed ad libitum with irradiated Ephestia kuehniella (Lepidoptera: Pyralidae) eggs and reared at constant environmental conditions $\left(24 \pm 1^{\circ} \mathrm{C}\right.$; $60 \pm 10 \%$ relative humidity; L:D 14:10 h photoperiod).

\section{(b) Experimental procedures}

For each population, the $\mathrm{G}_{3}$ generation consisted of 200 individuals (100 females and 100 males), which were placed randomly into five boxes $(9 \mathrm{~cm}$ high, $29 \mathrm{~cm}$ length and width) with 20 females and 20 males per box, for ten days to allow for mating. The 200 individuals from these 5 boxes were then distributed between two groups. The first group (60 females and 60 males) was used to produce eggs for the cannibalism experiments. The $H$. axyridis eggs used in these experiments were collected daily and kept at $-20^{\circ} \mathrm{C}$ for a maximum period of two weeks before use in the cannibalism experiments. We collected 2400 eggs for each population sample (totalling 24000 stored eggs). Individuals of the second group (40 females and 40 males for each population sample) were divided over two boxes and were used to obtain larvae and new adults for the cannibalism tests. To do so, we collected 25-35 egg clutches per population sample. A subsample of the larvae obtained from those eggs was used to 

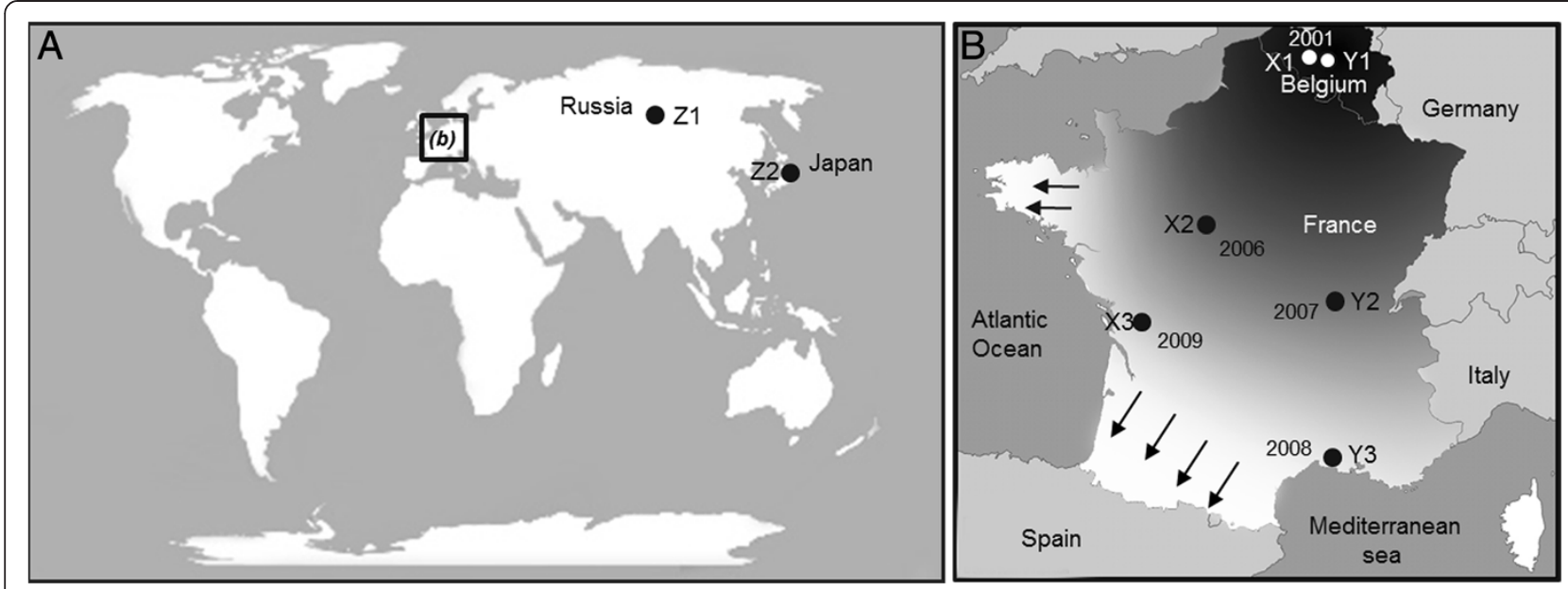

Figure 3 Geographic locations of the sampled populations of $\boldsymbol{H}$. axyridis. Note: (A) Geographical regions of the different native (Z1 and Z2) and invasive ( $X 1$ to $X 3$ and $Y 1$ to $Y 3$ ) sampled populations of $H$. axyridis. Closed circles correspond to locations where the two native populations have been sampled. (B) The Western European invasive populations of $H$. axyridis were sampled along two transects. Letters (X or $Y)$ correspond to the transect names, and years are the dates of the first observation of $\mathrm{H}$. axyridis at the sampled geographic localities. Two biocontrol populations reared in European laboratories since 1981, probably originating from China, were also used for the present study. See main text for details.

test the propensity for larval cannibalism on eggs. The remaining larvae were reared to adulthood in order to test the propensity for cannibalism of adult females.

To measure cannibalism rates, we placed individuals in a small cylindrical box measuring $5 \mathrm{~cm}$ diameter and $2.5 \mathrm{~cm}$ high. First instar larvae and adult females of each population sample were separated into two groups: low density (one individual per box), and high density (five larvae or three adult females per box). Larvae and adults had never consumed Harmonia eggs prior to being placed in the test arena. In the centre of each box we placed $15 \mathrm{H}$. axyridis eggs per individual on a piece of black paper (i.e.

Table 2 Sampling details of the ten studied $\boldsymbol{H}$. axyridis populations

\begin{tabular}{|c|c|c|c|c|c|}
\hline Biogeographic status & Sampling site locality & Sample code & Coordinates & Distance from outbreak core $(\mathrm{Km})$ & Date of first observation \\
\hline \multirow[t]{12}{*}{ Invasive } & Brussels (Belgium) & $\mathrm{X} 1$ & $50.839^{\circ} \mathrm{N}$ & 0 & 2001 \\
\hline & & & $4.368^{\circ} \mathrm{E}$ & & \\
\hline & Fondettes (France) & $\mathrm{x} 2$ & $47.402^{\circ} \mathrm{N}$ & 469 & 2006 \\
\hline & & & $0.637^{\circ} \mathrm{E}$ & & \\
\hline & Chizé (France) & $x_{3}$ & $46.148^{\circ} \mathrm{N}$ & 629 & 2009 \\
\hline & & & $0.424^{\circ} \mathrm{W}$ & & \\
\hline & Walhain (Belgium) & Y1 & $50.612^{\circ} \mathrm{N}$ & 0 & 2001 \\
\hline & & & $4.668^{\circ} \mathrm{E}$ & & \\
\hline & Quincieux (France) & Y2 & $45.909^{\circ} \mathrm{N}$ & 522 & 2007 \\
\hline & & & $4.758^{\circ} \mathrm{E}$ & & \\
\hline & Prade-le-lez (France) & Y3 & $43.698^{\circ} \mathrm{N}$ & 770 & 2008 \\
\hline & & & $3.863^{\circ} \mathrm{E}$ & & \\
\hline \multirow[t]{4}{*}{ Native } & Krasnoyarsk (Russia) & $\mathrm{Z1}$ & $56.001^{\circ} \mathrm{N}$ & N/A & N/A \\
\hline & & & $92.885^{\circ} \mathrm{E}$ & & \\
\hline & Fuchu (Japan) & Z2 & $34.57^{\circ} \mathrm{N}$ & N/A & N/A \\
\hline & & & $133.24^{\circ} \mathrm{E}$ & & \\
\hline \multirow[t]{2}{*}{ Biocontrol } & Valbonne (France) & W1 & N/A & N/A & N/A \\
\hline & Westerlo (Belgium) & W2 & $\mathrm{N} / \mathrm{A}$ & N/A & N/A \\
\hline
\end{tabular}

Note: Two populations were sampled in the native area ( $\mathrm{Z} 1$ and $\mathrm{Z} 2$ ), six in the European invaded area ( $\mathrm{X} 1$ to $\mathrm{X} 3$ and $\mathrm{Y} 1$ to $\mathrm{Y} 3$ ) and two populations originated from commercial biocontrol stocks (W1 and W2). For the European invasive populations, samples were collected along two transects starting from the outbreak core and ending near the invasion front (see Figure 3). N/A - not assessed. 
same ratio of eggs to predator in every box). Note that the eggs and the cannibalistic larvae or adults belong to the same population. We recorded the number of eggs eaten after $42 \mathrm{~h}$. (see Additional file 1: Figure S1 for illustration). The duration of 42 hours relied on practical grounds. We needed this period to allow discriminating between the tested populations. Too short a duration may hamper the behavioral differences to express while too long a duration would result in all eggs being eaten in all treatments. Preliminary experiments enabled us to find the most adequate duration.

A total of 950 first instar larvae (24 hours old) were tested with, for each population, $\mathrm{n}=75$ replicated tests for the high-density treatment and $n=20$ tests for the low-density treatment. A total of 650 adult females were tested with, for each population, $\mathrm{n}=45$ replicated tests for the high-density treatment and $n=20$ test for the low-density treatment. All adult females were 10-15 days old and initially fed with Ephestia eggs to standardize their feeding response.

\section{(c) Statistical analysis}

All statistical analyses were conducted using the JMP Pro 9 package (SAS Institute 2009). To study the propensity for cannibalism, the number of eggs eaten by individuals for each of the different treatments was compared using ANOVA, as follows. First, we focused on the six (invasive) European populations to test for potential differences in cannibalism rates that might take place during the spatial expansion in Western Europe. The model included the following factors: spatial level (core, intermediate and front, Figure 3), population sample nested in spatial level, density (low or high) as well as the interaction between density and spatial level. Second, we tested for differences in cannibalism rates among the three different types of $H$. axyridis populations. The model included the following factors: population type (native, invasive and biocontrol), population sample nested in population type, density (low or high) and the interaction between density and population type. Note that the analyses presented here include the six invasive Western European populations, but we obtained the same results when taking two of those populations randomly (results not shown). We performed all analyses separately for first instar larvae and adult females. Data sets for adult females and first instar larvae are provided in additional files 2 and 3, respectively.

\section{Additional files}

Additional file 1: Photos F1 illustrating the cannibalistic behaviour on eggs by (A) a larva (stage L1) and (B) an adult individual of Harmonia axyridis. (Photo courtesy of A. Tayeh).

Additional file 2: The data set of cannibalism by adult females. Additional file 3: The data set of cannibalism by first instar larvae.
Competing interests

The authors declare that they have no competing interests.

\section{Authors' contributions}

All authors read and approved the final manuscript, BF, AT and AE designed the experimental, AT, EL and NK collected samples, AT and BE analysed the data, BF, AT and AE drafted the manuscript.

\section{Acknowledgements}

We thank Bastien Poutout for technical assistance during laboratory experiments, Virginie Ravigné and Guillaume Laugier for comments and discussion on an earlier draft of the ms, and Cathleen Thomas for help in sample collection. This work was supported by a grant from the Agropolis Fondation (RTRA - Montpellier) to the BIOFIS project 1001-001.

\section{Author details}

${ }^{1}$ INRA, UMR, 1062, CBGP Montpellier, France. ${ }^{2}$ INRA, UMR 1355 Institut Sophia Agrobiotech, F-06903 Sophia Antipolis, France. ${ }^{3}$ Université de Nice-Sophia Antipolis, UMR Institut Sophia Agrobiotech, F-06903 Sophia Antipolis, France. ${ }^{4}$ CNRS, UMR 7254 Institut Sophia Agrobiotech, F-06903 Sophia Antipolis, France. ${ }^{5}$ V.N. Sukachev Institute of Forest, Siberian Branch of Russian Academy of Sciences, Akademgorodok 50/28, Krasnoyarsk 660036, Russia. ${ }^{6}$ Evolutionary Biology Group, School of Biological, Biomedical and Environmental Sciences, University of Hull, Cottingham Road, Kingston-Upon-Hull HU6 7RX UK. ${ }^{7}$ Department of Crop Protection, Ghent University, Coupure Links 653, B-9000 Ghent, Belgium.

Received: 2 August 2013 Accepted: 7 January 2014

Published: 5 February 2014

\section{References}

1. Fox LR: Cannibalism in natural-populations. Annu Rev Ecol Syst 1975, 6:87-106.

2. Polis GA: The evolution and dynamics of intraspecific predation. Annu Rev Ecol Syst 1981, 12:225-251.

3. Elgar MA, Crespi BA: Cannibalism. Ecology and evolution among diverse taxa. New York, USA: Oxford University Press; 1992.

4. Arnqvist $G$, Henriksson S: Sexual cannibalism in the fishing spider and a model for the evolution of sexual cannibalism based on genetic constraints. Evol Ecol 1997, 11(3):255-273.

5. Johnson JC: Sexual cannibalism in fishing spiders (Dolomedes triton): an evaluation of two explanations for female aggression towards potential mates. Anim Behav 2001, 61:905-914.

6. Mayntz D, Toft SR: Nutritional value of cannibalism and the role of starvation and nutrient imbalance for cannibalistic tendencies in a generalist predator. J Anim Ecol 2006, 75(1):288-297.

7. Stevens L: Cannibalism in beetles. In Cannibalism: ecology and evolution among diverse taxa. Edited by Elgar MA, Crespi BJ. Oxford: Oxford University Press; 1992:256-276.

8. Rudolf VHW, Kamo M, Boots M: Cannibals in space: the coevolution of cannibalism and dispersal in spatially structured populations. Am Nat 2010, 175(5):513-524.

9. Amundsen PA, Svenning MA, Siikavuopio SI: An experimental comparison of cannibalistic response in different Arctic charr (Salvelinus alpinus (L.)) stocks. Ecol Freshw Fish 1999, 8(1):43-48.

10. Croft BA, McMurty JA: Comparative studies on four strains of Typhlodromus acidentalis Nesbitt (Acarina: Phytoseiidae).IV: Life history studies. Acarologia 1972, 12s:460-470.

11. Via S: Cannibalism facilitates the use of a novel environment in the flour beetle, Tribolium castaneum. Heredity 1999, 82:267-275.

12. Park T, Mertz DB, Petrusewicz K: Genetic strains of Tribolium: their primary characteristics. Physiol Zool 1961, 34:62-80.

13. Wade MJ: Group selection among laboratory populations of Tribolium. Proc Natl Acad Sci USA 1976, 73(12):4604-4607.

14. Gabriel W: Overcoming food limitation by cannibalism: a model study on cyclopoids. Arch Hydrobiol 1985, 21:373-381.

15. Pfennig DW: Kinship and cannibalism. Bioscience 1997, 47(10):667-675.

16. Klug $H$, Bonsall MB: When to care for, abandon, or eat your offspring: The evolution of parental care and filial cannibalism. Am Nat 2007, 170(6):886-901.

17. Pfennig DW, Ho SG, Hoffman EA: Pathogen transmission as a selective force against cannibalism. Anim Behav 1998, 55:1255-1261. 
18. Goff PW, Stevens L: A test of Hamilton's rule: cannibalism and relatedness in beetles. Anim Behav 1995, 49:545-547.

19. Hamilton WD: The genetical evolution of social behaviour. I. J Theor Biol 1964, 7(1):1-16.

20. Wagner JD, Glover MD, Moseley JB, Moore AJ: Heritability and fitness consequences of cannibalism in Harmonia axyridis. Evol Ecol Res 1999, 1(3):375-388.

21. Wissinger SA, Sparks GB, Rouse GL, Brown WS, Steltzer H: Intraguild predation and cannibalism among larvae of detritivorous caddisflies in subalpine wetlands. Ecology 1996, 77(8):2421-2430.

22. Agashe D, Falk JJ, Bolnick Dl: Effects of founding genetic variation on adaptation to a novel resource. Evolution 2011, 65(9):2481-2491.

23. Lombaert E, Guillemaud T, Cornuet J-M, Malausa T, Facon B, Estoup A: Bridgehead Effect in the Worldwide Invasion of the Biocontrol Harlequin Ladybird. Plos One 2010, 5(3):e9743

24. Lombaert E, Guillemaud T, Thomas CE, Handley LJL, Li J, Wang S, Pang H, Goryacheva I, Zakharov IA, Jousselin E, et al: Inferring the origin of populations introduced from a genetically structured native range by approximate Bayesian computation: case study of the invasive ladybird Harmonia axyridis. Mol Ecol 2011, 20(22):4654-4670.

25. Osawa N: Population-field studies of the aphidophagous ladybird beetle Harmonia-axyridis (Coleoptera, Coccinellidae) - life-tables and key factoranalysis. Res Popul Ecol 1993, 35(2):335-348.

26. Osawa N: Sibling cannibalism in the ladybird beetle Harmonia-axyridis fitness consequences for mother and offspring. Res Popul Ecol 1992, 34(1):45-55

27. Osawa N: Sibling and non-sibling cannibalism by larvae of a lady beetle Harmonia-axyridis Pallas (Coleoptera, Coccinellidae) in the field. Res Popul Ecol 1989, 31(1):153-160.

28. Cottrell TE: Predation and cannibalism of lady beetle eggs by adult lady beetles. Biol Control 2005, 34(2):159-164.

29. Hodek I, Honek A: Ecology of Coccinellidae. Dordrecht, The Netherlands: Kluwer Academic Publishers; 1996.

30. Snyder WE, Joseph SB, Preziosi RF, Moore AJ: Nutritional benefits of cannibalism for the lady beetle Harmonia axyridis (Coleoptera: Coccinellidae) when prey quality is poor. Environ Entomol 2000, 29(6):1173-1179.

31. Hurst LD: The incidences and evolution of cytoplasmic male killers. Proc Royal Soc B-Biolog Sci 1991, 244(1310):91-99.

32. Majerus MEN: The impact of male-killing bacteria on the evolution of aphidophagous coccinellids. Eur J Entomol 2006, 103(1):1-7.

33. Elnagdy S, Majerus MEN, Handley LJL: The value of an egg: resource reallocation in ladybirds (Coleoptera: Coccinellidae) infected with male-killing bacteria. J Evol Biol 2011, 24(10):2164-2172.

34. Joseph SB, Snyder WE, Moore AJ: Cannibalizing Harmonia axyridis (Coleoptera : Coccinellidae) larvae use endogenous cues to avoid eating relatives. J Evol Biol 1999, 12(4):792-797.

35. Kim H, Lee S, Jang Y: Macroevolutionary patterns in the aphidini aphids (Hemiptera: Aphididae): diversification, host association, and biogeographic origins. Plos One 2011, 6(9):e24749

36. Kawai A: Analysis of the aggregation behavior in the larvae of Harmonia axyridis Pallas (Coleoptera: Coccinellidae) to prey colony. Res Populat Ecol 1976, 18(1):123-134.

37. Brown HD: The behavior of newly hatched coccinellid larvae (Coleoptera: Coccinellidae). J Entomolog Soc South Afr 1972, 35:149-157.

38. Dixos AFG: An experimental study of the searching behaviour of the predatory coccinellid beetle Adalia decempunctata (L.). f Anim Ecol 1959, 28:259-281.

39. Kajita $Y, J J ~ O, J J$ S: Intraspecific alkaloid variation in ladybird eggs and its effects on con- and hetero-specific intraguild predators. Oecologia 2010, 163:313-322.

40. Fiumera AC, Parker PG, Fuerst PA: Effective population size and maintenance of genetic diversity in captive-bred populations of a Lake Victoria Cichlid. Conserv Biol 2000, 14(3):886-892.

41. Lombaert E, Malausa T, Devred R, Estoup A: Phenotypic variation in invasive and biocontrol populations of the harlequin ladybird, Harmonia axyridis. Biocontrol 2008, 53(1):89-102.

42. Facon B, Crespin L, Loiseau A, Lombaert E, Magro A, Estoup A: Can things get worse when an invasive species hybridizes? The harlequin ladybird Harmonia axyridis in France as a case study. Evol App/ 2011, 4(1):71-88.
43. Tayeh A, Estoup A, Laugier G, Loiseau A, Turgeon J, Toepfer S, Facon B: Evolution in biocontrol strains: insight from the harlequin ladybird Harmonia axyridis. Evol Appl 2012, 5(5):481-488.

44. Turgeon J, Tayeh A, Facon B, Lombaert E, De Clercq P, Berkvens N, Lundgren JG, Estoup A: Experimental evidence for the phenotypic impact of admixture between wild and biocontrol Asian ladybirc (Harmonia axyridis) involved in the European invasion. J Evol Biol 2011, 24(5):1044-1052.

45. Excoffier L, Foll M, Petit RJ: Genetic consequences of range expansions. Ann Rev Ecol Evol Syst 2009, 40:481-501.

46. Dong Q, GA P: The dynamics of cannibalistic populations: a foraging perspective. In Cannibalism - ecology and evolution among diverse taxa. Edited by Elgar MA, Crespi BJ. Oxford: Oxford Science; 1992:13-37.

47. Brown PMJ, Thomas CE, Lombaert E, Jeffries DL, Estoup A, Handley L-JL: The global spread of Harmonia axyridis (Coleoptera: Coccinellidae): distribution, dispersal and routes of invasion. Biocontrol 2011, 56(4):623-641.

48. Adriaens T, San Martin y Gomez G, Maes D: Invasion history, habitat preferences and phenology of the invasive ladybird Harmonia axyridis in Belgium. Biocontrol 2008, 53(1):69-88.

49. Ferran A, Dixon AFG: Foraging behavior of ladybird larvae (Coleoptera, Coccinellidae). Eur J Entomol 1993, 90(4):383-402.

doi:10.1186/1471-2148-14-15

Cite this article as: Tayeh et al:: Cannibalism in invasive, native and biocontrol populations of the harlequin ladybird. BMC Evolutionary Biology 2014 14:15.

\section{Submit your next manuscript to BioMed Central and take full advantage of:}

- Convenient online submission

- Thorough peer review

- No space constraints or color figure charges

- Immediate publication on acceptance

- Inclusion in PubMed, CAS, Scopus and Google Scholar

- Research which is freely available for redistribution 